\title{
The influence of scan duration on pulmonary capillary hemorrhage induced by diagnostic ultrasound
}

\author{
Douglas L. Miller ${ }^{1}$, Zhihong Dong ${ }^{1}$, Chunyan Dou ${ }^{1}$, and Krishnan Raghavendran ${ }^{2}$ \\ ${ }^{1}$ Department of Radiology, University of Michigan, Ann Arbor, MI. 48109 \\ ${ }^{2}$ Department of Surgery, University of Michigan, Ann Arbor, MI. 48109
}

\begin{abstract}
Diagnostic ultrasound can induce pulmonary capillary hemorrhage $(\mathrm{PCH})$ in rats and display this as "comet-tail" artifacts (CTA) after a time delay. To test the hypothesis that no PCH occurs for brief scans, anesthetized rats were scanned using a $6 \mathrm{MHz}$ linear array for different durations. PCH was characterized by ultrasound CTAs, micro-computed tomography $(\mu \mathrm{CT})$ and measurements of fixed lung tissue. The $\mu \mathrm{CT}$ images showed regions of $\mathrm{PCH}$, sometimes penetrating the entire depth of a lobe, which were reflected in the fixed tissue measurements. At $-3 \mathrm{~dB}$ power, $\mathrm{PCH}$ was substantial for $300 \mathrm{~s}$ scans but not significant for $25 \mathrm{~s}$ scans. At $0 \mathrm{~dB}, \mathrm{PCH}$ was not strongly dependent on scan durations of $300 \mathrm{~s}$ to $10 \mathrm{~s}$. Contrary to the hypothesis, CTAs were not evident during most $10 \mathrm{~s}$ scans $(\mathrm{p}>0.05)$, but $\mathrm{PCH}$ was significant $(\mathrm{p}=0.02)$, indicating that $\mathrm{PCH}$ could occur without evidence of the injury in the images.
\end{abstract}

\section{Keywords}

Pulmonary ultrasound; Comet tail artifact; Pulmonary capillary hemorrhage; Pulmonary microcomputed tomography; Diagnostic ultrasound safety

\section{Introduction}

Diagnostic ultrasound can induce capillary hemorrhage in mammalian lung, depending on physical and biological conditions. Pulmonary capillary hemorrhage ( $\mathrm{PCH})$ induced by ultrasound has been studied intermittently since its discovery by Child et al. (1990). Over this period, the use of trans-thoracic ultrasound for pulmonary examination has grown to be an important tool for diagnosis in the point of care settings of emergency and intensive care (Volpicelli, 2013; Lichtenstein, 2014). Features in the diagnostic images, such as comet-tail

Corresponding author: Douglas L. Miller, 3240A Medical Sciences Building I, University of Michigan Health System, 1301 Catherine Street, Ann Arbor MI 48109-5667, Tel: (734) 647-3344, FAX: (734) 764-8541, douglm@umich.edu.

Publisher's Disclaimer: This is a PDF file of an unedited manuscript that has been accepted for publication. As a service to our customers we are providing this early version of the manuscript. The manuscript will undergo copyediting, typesetting, and review of the resulting proof before it is published in its final citable form. Please note that during the production process errors may be discovered which could affect the content, and all legal disclaimers that apply to the journal pertain.

Supplementary Data

1. A video clip assembled from a stack of $\mu \mathrm{CT}$ images of the same region shown in the right image of Fig. 2

2. A video clip of one $10 \mathrm{~s}$ scan (Group G), which produced discernable CTAs (see Fig. 5c). 
artifacts (CTAs), are indicative of diseases involving the alveolar-interstitial interphase, pulmonary edema and pulmonary effusion, among other problems. When $\mathrm{PCH}$ occured, the causative diagnostic ultrasound image displayed the development of PCH during scanning in rats as the initiation and growth of CTAs (Miller, 2012), a remarkable exhibition of the power of the ultrasonic energy transmitted into the chest and of the sensitivity of ultrasonic imaging to detect pulmonary injury. The $\mathrm{PCH}$ bioeffect is not yet fully understood relative to the complex mix of clinical diagnostic ultrasound modes and patient conditions examined. More information is urgently needed to develop the best possible safety advice for sonographers.

Early research showed that the ultrasonically induced $\mathrm{PCH}$ occurs in mice, rats and pigs (American Institute of Ultrasound in Medicine, 2000; Church et al. 2008). PCH can be characterized by a threshold value of the ultrasonic pulse pressure amplitude in MPa (or other relevant exposure metric) for a specific set of experimental conditions. PCH thresholds have been assessed for variations in pulsed ultrasound beam width, pulse length, frequency, total on-time and exposure duration (Church and O'Brien, 2007). The age of the subject has also been evaluated as a risk factor, with some indication of increased sensitivity with age (Dalecki et al. 1997; Obrien et al. 2003). Recently, we discovered that the PCH was strongly influenced by anesthesia methods in our animal tests (Miller et al. 2015a), which adds complex biological parameters into the mix of physical parameters relevant to the $\mathrm{PCH}$ problem. Most early studies were performed using laboratory pulsed ultrasound systems configured for relevance to diagnostic ultrasound. The results of a comparison between PCH from diagnostic and laboratory systems indicated that the diagnostic scanning results were comparable with the earlier findings, which provides a large and reasonably consistent data base (Miller et al. 2015b). The diagnostic ultrasound frequency does not strongly influence the threshold for PCH (Miller et al. 2015c), which questions the use of the on-screen Mechanical Index as a safety index for gauging the likelihood of PCH.

In addition to the dose-response trends for ultrasonic output parameters, the exposure duration appears to be a key dosage parameter (Miller et al. 2015b). For example, a $2.0 \mathrm{MPa}$ threshold for $2.8 \mathrm{MHz}, 11.6 \mu$ s pulses, $1 \mathrm{~ms}$ interval and $10 \mathrm{~s}$ exposure duration (O'Brien et al. 2003) was substantially higher than our $0.75 \mathrm{MPa}$ threshold at $1.5 \mathrm{MHz}$ for $10 \mu$ s pulses, $25 \mathrm{~ms}$ interval and $300 \mathrm{~s}$ exposure duration, even though the numbers of pulses delivered and total on-time were similar. This observation suggests an important role for the exposure duration in the $\mathrm{PCH}$ threshold, an unexpected finding because the longer duration greatly reduced the average intensity of the energy delivered. However, for constant pulsing parameters, Raeman et al. (1996) found that the threshold for $\mathrm{PCH}$ in mice was about the same for $20 \mathrm{~s}$ to $300 \mathrm{~s}$ exposures. Interestingly, for diagnostic ultrasound, the influence of exposure duration on outcome may be directly determinable during scanning, based on the observation of the initiation and growth of CTAs in the ultrasound image. Previous work (Miller, 2012) showed variation of the time delay between the start of scanning and the initiation of CTAs in the image for 5 min scans, which suggests that brief scans might allay the risk of injury. There may be an exposure-scan duration threshold for PCH. Indeed, monitoring the ultrasound image itself for CTA initiation might be a plausible safety strategy. However, for different ultrasonic frequencies, the detection of CTAs was found to be somewhat difficult for lower frequencies with lower resolution (Miller et al. 2015c). 
This study was undertaken to provide information on the dependence of $\mathrm{PCH}$ on different exposure-scan durations, rather than just the time of CTA initiation during 5 min scans. PCH areas on the lung surface were measured as before, but were considered inadequate to fully describe the PCH impact. The severity of some pulmonary conditions may be indicated by the length of the comets (Gargani et al. 2009; Weitzel et al. 2015). Also, the number of CTAs (also called "B lines") appears to have a correlation with the extent of parenchymal changes in CT images (Martelius et al. 2016). However, the CTAs do not actually provide quantitative data on $\mathrm{PCH}$ depth. The nature and depth of the $\mathrm{PCH}$ regions inside the lung were evaluated in the current study. Histological evaluations can provide information on depth, but do not clarify the nature of the $\mathrm{PCH}$. To clarify the precise extent of the $\mathrm{PCH}$ relative to its appearance in radiological observation, micro-computed tomography $(\mu \mathrm{CT})$ images were obtained. In addition, PCH depths and volumes were measured in fixed tissue samples and confirmed as realistic for assessment of in situ PCH by comparison to the $\mu \mathrm{CT}$ images.

\section{Materials and Methods}

All in vivo animal procedures were conducted with the approval and guidance of the University Committee on Use and Care of Animals (UCUCA) of the University of Michigan. In this study, a total of 46 female rats (Sprague Dawley, Charles River, Wilmington, MA, USA) weighing an average of $257 \pm 23 \mathrm{gm}$ were tested, with one rat lost from the study due to anesthetic death. Anesthesia was induced by intraperitoneal injection (IP) of Ketamine $(75 \mathrm{mg} / \mathrm{kg})$ plus dexmedetomidine $(0.5 \mathrm{mg} / \mathrm{kg})$. The specific anesthesia techniques can be an important factor in studies of ultrasound induced PCH (Miller et al. 2015a). Most PCH studies in rodents have used ketamine and xylazine (a veterinary sedative) for anesthesia. Here, dexmedetomidine, a common human clinical sedative and anxiolytic (Mason et al. 2011) which gives similar PCH results even in the normal human dose range (Miller et al. 2016), replaced xylazine in the anesthetic mixture. The right thorax of all rats was shaved and depilated for ultrasound transmission. The rats were mounted on a plastic board and partly immersed in a $38^{\circ} \mathrm{C}$ degassed water bath together with the ultrasound probe. This exposure method has reliable ultrasound coupling, and maintains the body temperature of the rats. Physiological data was collected at the time of ultrasound scanning using a pulse oximeter (SurgiVet V3395 TPR, Smiths Medical Inc. St Paul, MN USA), and visual observation of respiration. The average values were: $244 \pm 12 \mathrm{bpm}$ heart rate, $80 \pm 4 \% \mathrm{SpO}_{2}$, and $73 \pm 15$ breaths per minute. Anesthesia was maintained until sacrifice for sample collection $1 \mathrm{~h}$ after scanning.

\section{Ultrasound scanning}

A GE Vivid 7 Dimension (GE Vingmed Ultrasound, Horten NO) ultrasound machine was used for imaging and exposure scanning. The $7 \mathrm{~L}$ probe was used in B Mode at the $6.0 \mathrm{MHz}$ setting with $4 \mathrm{~cm}$ depth, $1.56 \mathrm{~cm}$ focus and 63.1 frames per s (fps). For one group of rats, the frames were triggered intermittently at $5 \mathrm{fps}$. The probe was aimed with a $-20 \mathrm{~dB}$ power setting approximately horizontally at the right side of the rat to position the lung surface at an image depth of 1.25-1.75 $\mathrm{cm}$ at the level of the cranial or middle lobes, and avoiding ribs as much as possible. 
For a test scan, the power setting was raised to the desired level of $0 \mathrm{~dB}$ or $-3 \mathrm{~dB}$, and timed for the desired duration. To accurately time $10 \mathrm{~s}$ scans, a paddle was inserted between the probe and the rat while the power was raised, and then quickly removed for scanning with the ultrasound stopped by the freeze control after $10 \mathrm{~s}$. The in situ exposure parameters at the depth of the lung surface were estimated for the different power settings by measurements with calibrated hydrophone (HGL0200, Onda, Sunnyvale, CA, USA). Measurements were made of the ultrasound pulses attenuated by five different rat chest wall samples, and are listed in Table 1. The center frequency was estimated from the duration of one cycle at $-20 \mathrm{~dB}$ to be $5.8 \mathrm{MHz}$. The pulse repetition frequency was $12.2 \mathrm{kHz}$ for the 350 ns duration pulses. The active width of the probe was $4.8 \mathrm{~cm}$ and the $-6 \mathrm{~dB}$ thickness (beam width) of the scan plane was $2.2 \mathrm{~mm}$.

\section{Micro-Computed Tomography}

Although ultrasound is useful for examining the surface of the lung, plane film x-rays or CT scanning remains the gold-standard for evaluation of pulmonary contusion (see, for example, Miller (2006)). $\mu \mathrm{CT}$ was performed at the University of Michigan Center for Molecular Imaging using a SkyScan1176 scanner (Bruker microCT, 2550 Kontich, Belgium). The $\mu \mathrm{CT}$ produced stacks of 1,360 images that were 1016 by 1016 pixels with $35 \mu \mathrm{m}$ resolution, and $35 \mu \mathrm{m}$ spacing. $\mu \mathrm{CT}$ Imaging was performed on the thorax of 12 rats, including 2 shams, 5 scanned for $100 \mathrm{~s}$ at $0 \mathrm{~dB}$ and 5 scanned for $300 \mathrm{~s}$ at $0 \mathrm{~dB}$, as listed in Table 1 . The ultrasound-scanned rats were transported to the University of Michigan Center for Molecular Imaging for the $\mu \mathrm{CT}$ scanning, which introduced a time delay of about $1 \mathrm{~h}$ between ultrasound and $\mu \mathrm{CT}$ imaging. The rats were sacrificed a few min before $\mu \mathrm{CT}$ scanning and the trachea was intubated. During scanning the lungs were minimally inflated with $20 \mathrm{~cm}$ $\mathrm{H}_{2} \mathrm{O}$ of air. At the conclusion of scanning, the tracheal tube was tied off to prevent alveolar collapse and maintain lung morphology.

The $\mu \mathrm{CT}$ data was processed to determine the approximate size of the $\mathrm{PCH}$ lesions using image analysis software (CT Analyzer V.1.14.1, Bruker microCT, 2550 Kontich, Belgium). The 16 bit per pixel images were first converted to 8 bit, including limiting the range of Hounsfield units to -500 to -1000 (from $-1,000$ to $+1,000$ ) in order to display the lung tissue with good contrast. The PCH was depicted clearly for the two groups, and its identification was verified by comparison to shams, which helped in the appraisal of light and dark artifacts of the $\mu \mathrm{CT}$ images. The artifacts produced some uncertainty in the precise localization of the $\mathrm{PCH}$, especially near ribs and sternum, and precluded the use of the $\mu \mathrm{CT}$ imaging for low-effect (threshold) conditions. The right lung volume containing the PCH was localized to within a rectangular box, typically $20 \mathrm{~mm}$ by $20 \mathrm{~mm}$ (x,y) in each image and $24 \mathrm{~mm}(\mathrm{z})$ deep. At 20 slice $(0.69 \mathrm{~mm})$ intervals, the center of the PCH at the chest wall was located by $\mathrm{x}, \mathrm{y}, \mathrm{z}$ coordinates, and then the depth, surface width and area of the PCH in the slice was measured. This allowed calculation of the approximate area of the $\mathrm{PCH}$ on the lung surface as the sum (for all the slices measured) of the surface width times $0.69 \mathrm{~mm}$, and the volume of the $\mathrm{PCH}$ as the sum of the area times $0.69 \mathrm{~mm}$. This process was repeated for each identifiable $\mathrm{PCH}$ volume, for both the cranial and medial lobes if needed. 


\section{Lung Sample Fixation and Scoring}

For rats not receiving $\mu \mathrm{CT}$ scanning, sacrifice as delayed for $1 \mathrm{~h}$ to approximate the delayto-sacrifice for the $\mu \mathrm{CT}$ scanned rats. For all rats, the trachea was tied off with an air pressure of $20 \mathrm{~cm} \mathrm{H}_{2} \mathrm{O}$ and the entire closed thorax was isolated and immersed in neutral buffered formalin. This procedure was intended to fix the lungs as closely as possible in the positions and volumes they occupied during ultrasound and $\mu \mathrm{CT}$ scanning. However, this was not entirely successful, due to some re-arrangement of the lungs between the vertical mounting in the water bath for ultrasound and the horizontal position in the $\mu \mathrm{CT}$ machine.

After fixation the lungs were dissected from the thorax and placed into $70 \%$ ethanol for subsequent handling. The lungs were photographed with a stereo microscope and camera (Spot Flex, Diagnostic Instruments Inc., Sterling Heights, MI USA). The surface length, width and area of the PCH was then measured with image analysis software (Spot v. 5.1, Diagnostic Instruments, Inc., Sterling Heights, MI USA). The PCH regions could be identified readily by visual inspection with the stereo microscope. Each lobe with PCH was isolated and the length of the PCH was sliced into $\sim 2 \mathrm{~mm}$ thick cross-sections. Each cross section was photographed and measured to obtain the depth of hemorrhage visible in the section. These data were used to determine the mean depth of the PCH and then to calculate the $\mathrm{PCH}$ volume as the product of mean depth and surface area. This method for depth and volume determination was similar to that used by Zachary et al. (2001), except multiple measurements were needed here to characterize the long narrow $\mathrm{PCH}$ produced by $\mathrm{B}$ mode scanning, compared to a single fixed beam exposure. In addition, the PCH here seemed to remain about the same width with depth, rather than forming a conical shape (Zachary et al, 2001). A few sections were selected for histology and were processed as paraffin sections with hematoxylin and eosin staining.

\section{Measured endpoints and experimental plan}

The testing was arranged in 8 groups of 5 rats, see Table 2 . The conditions were set to observe the $\mathrm{PCH}$ produced by the maximum power setting $(0 \mathrm{~dB})$ for exposure durations of $300 \mathrm{~s}$ (i. e., the 5 min duration used previously), $100 \mathrm{~s}, 25 \mathrm{~s}$ and $10 \mathrm{~s}$. The influence of duration was also assessed for $300 \mathrm{~s}$ and $25 \mathrm{~s}$ durations at $-3 \mathrm{~dB}$. In addition, a $300 \mathrm{~s}$ duration scan condition utilized intermittent imaging at $5 \mathrm{fps}$ (Group H). This condition delivered 1,500 frames at $0 \mathrm{~dB}$ over $300 \mathrm{~s}$, compared to 1,577 frames (i. e. approximately the same number) at $0 \mathrm{~dB}$ over $25 \mathrm{~s}$ for Group E, and 18,900 at $0 \mathrm{~dB}$ over $300 \mathrm{~s}$ for Group B. These tests were intended to assess the relative influence of the total number of frames delivered and the overall scan duration. $\mu \mathrm{CT}$ scanning was conducted to assess the appearance of the $\mathrm{PCH}$ in CT imaging and to provide in situ measurements of the $\mathrm{PCH}$ shape and volume for comparison to the fixed lung samples. The $\mu \mathrm{CT}$ scanning was conducted only for $0 \mathrm{~dB}$ for $300 \mathrm{~s}$ and $100 \mathrm{~s}$, because the sensitivity of the $\mu \mathrm{CT}$ was less than that of simple visual observation of the effected lungs. Two shams were also scanned to aid in identification of image features or artifacts not associated with PCH. Statistical comparisons between groups were performed using SigmaPlot for Windows V. 11.0 (Systat Software Inc., San Jose CA, USA), with statistical significance assumed at $\mathrm{P}<0.05$. 


\section{Results}

The ultrasound images displayed the progression of the $\mathrm{PCH}$, for which the length of CTAs across the image approximated the length of the $\mathrm{PCH}$ on the lung surface. An example of the ultrasound images before and after a $0 \mathrm{~dB}$ scan for $100 \mathrm{~s}$ (Group D) are shown in Fig. 1. The mean widths of the bright-line lung surface image are listed in Table 3 for all groups.

A $\mu$ CT image is shown in Fig. 2 of the same lung shown in Fig. 1 by ultrasound. The $\mu \mathrm{CT}$ images are shown in the radiology configuration (the right lung is on the left side of the image). The PCH is evident in the right medial lobe at the anterior chest wall, while the caudal lobe appears to be free of PCH. The PCH image level and texture was similar to the heart or chest wall. The medial lobe is outlined to show the indistinct pleural boundary between the heart and chest wall and the perceived borders of the PCH are also shown. Although airways often were apparent within the PCH area, the blood vessels were not. The $\mu \mathrm{CT}$ images included the entire lung volume and some tissue above and below the lungs; however, volume rendering of the PCH lesions was found to be difficult, due to the lack of contrast difference between the $\mathrm{PCH}$, blood and tissue, and was not used for quantification. A video made up of $\mu \mathrm{CT}$ images containing the entire PCH shown in Fig. 2 is presented as Supplemental Data 1 so that the variation of its appearance with axial position can be appreciated. The appearance of $\mathrm{PCH}$ in the $\mu \mathrm{CT}$ images was not unlike clinical CT images of post-traumatic human pulmonary contusion.

The fixed lung sample for the same test as shown in Fig. 1 and 2 is shown in Fig. 3. The $\mathrm{PCH}$ is outlined to more clearly display the two surface areas. The $\mathrm{PCH}$ lengths were measured on the photographs and summed to obtain total lengths for comparison to the lengths of CTAs in the ultrasound images and are listed in Table 3. Figure 4 compares the $\mathrm{CTA}$ and $\mathrm{PCH}$ lengths for the $0 \mathrm{~dB}$ tests at different durations. The CTAs appeared to be diagnostic for the length of $\mathrm{PCH}$ on the lung surface, except for the brief $10 \mathrm{~s}$ scans (group $\mathrm{G})$. All of the lungs from group $\mathrm{G}$ showed clear $\mathrm{PCH}$, but only three of the ultrasound images contained clear CTAs. Two examples of group $\mathrm{G}$ are shown in Fig. 5, for which the smaller PCH did not appear in the ultrasound image. A video clip recorded during a $10 \mathrm{~s}$ scan is presented as Supplemental Data 2 to illustrate the CTA development.

The PCH volume was also characterized by measurements of the fixed lungs. Measurements of the depth, area and calculated volume of the PCH are listed in Table 4 for all groups. The surface length and area of PCH were measured on photographs and totaled for each sample. The PCH area was not significantly different from shams for group F ( $-3 \mathrm{~dB}, 25 \mathrm{~s})$, with only 3 of the 5 tests giving any detectable $\mathrm{PCH}$, but was significantly different for all the other groups, including group $\mathrm{G}(0 \mathrm{~dB}, 10 \mathrm{~s})$. The depth of the PCH regions was obtained by cutting thick cross sections and measuring the apparent hemorrhage depth in photographs. An example of a slab-cross section cut from the medial lobe PCH is shown in Fig. 3, together with a histological image made from the slab. The ultrasound scan impinged upon the surface with the outlined PCH penetrating essentially the entire depth of the lobe for this example. 
The findings from the $\mu \mathrm{CT}$ images and fixed tissue photographs were in approximate agreement, with no significant differences between depth, area and volume measurements. The measurements were quite variable; for example, the mean $\mathrm{PCH}$ volume for the $100 \mathrm{~s}$ duration was paradoxically larger than for the $300 \mathrm{~s}$ duration (although not significantly different). Some of the variability was due to chance variations in the scanned region. The PCH depth often penetrated the entire thickness of the lobe but this occurred in thin or thick regions of the lobes, yielding low or high volume values even though the impact might be considered to be the same (i. e. penetration of the lobe). The observation of the bright red PCH areas on the lung surface was the most sensitive method to detect the bioeffect (e. g. for threshold determinations), and small PCH regions would not be identifiable in the $\mu \mathrm{CT}$ images. The depth measurements were the important new parameter for this study. The depths found from the $\mu \mathrm{CT}$ and tissue are compared in Fig. 6 and have a slope of 0.75 and coefficient of determination $\mathrm{r}^{2}=0.72$.

The PCH area for group $\mathrm{G}(0 \mathrm{~dB}, 10 \mathrm{~s})$ was significantly smaller $(\mathrm{p}<0.001)$ than that of group B $(0 \mathrm{~dB}, 300 \mathrm{~s})$. However, as shown in Fig. 7 , the variation of $\mathrm{PCH}$ with scan duration was small in the context of the 30 fold duration range. The depths and volumes were not significantly different for group $\mathrm{G}$ and B. Group E $(0 \mathrm{~dB}, 25 \mathrm{~s})$ and group $\mathrm{H}(0 \mathrm{~dB}$, intermittent scan for $300 \mathrm{~s}$ ) did not have significantly different depths, areas or volumes, which indicated that scan duration was not important for approximately equal numbers of frames. Group $\mathrm{H}$ had a significantly smaller $\mathrm{PCH}$ area than group B, suggesting that the total number of frames was important in the result. Comparing group B with group $C(-3 \mathrm{~dB}, 300$ $\mathrm{s})$, the mean depth was significantly greater $(\mathrm{p}<0.01)$, but the areas and volumes were not. This again reflects the relatively low result for group $\mathrm{B}$ (also less than group $\mathrm{D}$, with a shorter duration as noted above). However, group F ( $-3 \mathrm{~dB}, 25 \mathrm{~s})$ had significantly lower $(p<0.05)$ results than group $E$ and group $C$. The different trends for the $-3 \mathrm{~dB}$ tests compare to the $0 \mathrm{~dB}$ tests is illustrated in Fig. 7. The lower power setting had a greatly reduced impact for the $25 \mathrm{~s}$ scan duration and the $\mathrm{PCH}$ was not significantly different from shams. Two way ANOVA for power $(0 \mathrm{~dB},-3 \mathrm{~dB})$ and duration $(25 \mathrm{~s}, 300 \mathrm{~s})$ indicated no significant interaction between power and duration for the area results, but a significant interaction $(\mathrm{p}=0.014)$ for the volume results.

\section{Discussion and Conclusions}

This study was undertaken to provide information on the nature of the diagnostic ultrasound induced PCH lesions and to determine the dependence of $\mathrm{PCH}$ on exposure-scan durations. CTAs in the ultrasound images and PCH areas on the lung surface were measured as before, but were considered inadequate to fully characterize the $\mathrm{PCH}$. Hence, the nature and depth of the $\mathrm{PCH}$ regions inside the lung were evaluated using $\mu \mathrm{CT}$ imaging and measured in fixed lung samples to provide data on depth of the lesions.

The ultrasound images displayed the progression of the $\mathrm{PCH}$, for which the width of CTAs approximated the length of the PCH on the lung surface, see Figure 1 and Table 3, but did not provide data on the depth of the hemorrhages. The $\mu \mathrm{CT}$ provided detailed images of the PCH. An example of the $\mu \mathrm{CT}$ images is shown in Fig. 2 of the same lung shown in Fig. 1 by ultrasound. A video clip showing the progression of the CTAs during a $10 \mathrm{~s}$ scan, and a set 
of $\mu \mathrm{CT}$ images (presented as a video clip) containing an entire $\mathrm{PCH}$ volume are also provided as supplemental data.

Figure 4 compares the CTA widths and PCH lengths for the $0 \mathrm{~dB}$ tests at different durations. The CTAs appeared to be diagnostic for the length of PCH on the lung surface, except for the brief $10 \mathrm{~s}$ scans (group G). The $10 \mathrm{~s}$ scans all produced PCH that was clearly evident on the lung surface, but only three were detected by the presence of clear CTAs. The lack of detection for some lesions seems likely to be related to the ultrasound image resolution and the size of the PCH lesions. The two $10 \mathrm{~s}$ scans without CTAs produced PCH 1.2 and 1.6 mm (Fig.5a) in width, while the $10 \mathrm{~s}$ scans with CTAs produced PCH 3.1, 2.5 (Fig. 5b) and $2.2 \mathrm{~mm}$ in width. The smaller PCH lesions apparently were too small to be resolved by the machine and displayed on screen as CTAs.

Measurements of the depth, area and calculated volume of the $\mathrm{PCH}$ are listed in Table 4 for all groups. The findings from the $\mu \mathrm{CT}$ images and fixed tissue photographs were in approximate agreement (e. g. see Fig. 6), confirming the use of the in situ fixation method for realistic appraisal of the in situ configuration of the PCH (aside from some shifting of the lung lobes). The PCH area for $0 \mathrm{~dB}, 10 \mathrm{~s}$ scans was smaller than that of $0 \mathrm{~dB}, 300 \mathrm{~s}$ scans but much greater than might have been expected for the 30 fold reduction in duration. The result for the intermittent $5 \mathrm{~Hz}$ frame rate was the same as for the normal frame rate when the same total number of frames was delivered.

The dependence of PCH area on duration for $0 \mathrm{~dB}$ scans, shown in Fig. 7, is a steep linear increase to a plateau. This trend was probably due to the surface PCH filling the beamscanned area. The average bright lung surface image was $18.5 \mathrm{~mm}$ long, and the beam width was $2.2 \mathrm{~mm}$, giving $41 \mathrm{~mm}^{2}$ for the maximum PCH area (without taking lung sliding into account, which would widen the PCH), which is achieved in Fig. 7. Likewise the PCH volume can achieve a maximum value approximated by the maximum area times the thickness of the effected lung lobe, typically in the range of 1-4 mm, giving 41-164 $\mathrm{mm}^{3}$ (again neglecting lung sliding or migration of the hemorrhage outside the beam), which is reflected in Fig. 7 as a mean of about $100 \mathrm{~mm}^{3}$ and large error bars. The $-3 \mathrm{~dB}$ scans for 25 $\mathrm{s}$ were greatly reduced (to insignificance) compared to the $-3 \mathrm{~dB}, 300 \mathrm{~s}$ scans and $25 \mathrm{~s}$ scans, see Figure 7. This finding suggests that the threshold power setting for $25 \mathrm{~s}$ scans would be less than that for $300 \mathrm{~s}$ scans, and that a duration threshold greater than $25 \mathrm{~s}$ may be definable for the lower power setting. For the $0 \mathrm{~dB}$ scanning, there did not appear to be a duration threshold, at least down to $10 \mathrm{~s}$ scans.

Overall, these results show that the diagnostic ultrasound induced PCH was visualized by computed tomography and was similar in appearance to reported observations of lung contusion. For the $0 \mathrm{~dB}$ power setting, the dependence of $\mathrm{PCH}$ on scan duration was minimal from $300 \mathrm{~s}$ down to $10 \mathrm{~s}$. The $10 \mathrm{~s}$ scans produced a significant $\mathrm{PCH}$ effect which was not always discernable in the image as CTAs. Thus, monitoring the image for CTAs may not be a reliable means to gauge the occurrence of PCH. The $-3 \mathrm{~dB}$ scans did not produce significant $\mathrm{PCH}$ for the $25 \mathrm{~s}$ scan duration. During normal clinical scanning, $\mathrm{PCH}$ may be avoidable simply by reduction of the ultrasound power setting on the machine. 
Further work is needed to understand the basic biophysical mechanism of action leading to $\mathrm{PCH}$, and to translate these findings to human clinical relevance.

\section{Supplementary Material}

Refer to Web version on PubMed Central for supplementary material.

\section{Acknowledgments}

We thank Prof. Craig Galban, Carlos Espinoza, and Amanda Fair of the University of Michigan Center for Molecular Imaging for performing the $\mu \mathrm{CT}$ scans and helping with their interpretation. This study was supported by the National Institutes of Health, National Heart Lung and Blood Institute, via grant number HL116434.

\section{References}

American Institute of Ultrasound in Medicine. Section 4--bioeffects in tissues with gas bodies. J Ultrasound Med. 2000; 19:97-108. 154-168. [PubMed: 10680616]

Child SZ, Hartman CL, Schery LA, Carstensen EL. Lung damage from exposure to pulsed ultrasound. Ultrasound Med Biol. 1990; 16:817-825. [PubMed: 2095012]

Church CC, O'Brien WD Jr. Evaluation of the threshold for lung hemorrhage by diagnostic ultrasound and a proposed new safety index. Ultrasound Med Biol. 2007; 33:810-818. [PubMed: 17383801]

Church CC, Carstensen EL, Nyborg WL, Carson PL, Frizzell LA, Bailey MR. The risk of exposure to diagnostic ultrasound in postnatal subjects: nonthermal mechanisms. J Ultrasound Med. 2008; 27:565-592. [PubMed: 18359909]

Dalecki D, Child SZ, Raeman CH, Cox C, Penney DP, Carstensen EL. Age dependence of ultrasonically induced lung hemorrhage in mice. Ultrasound Med Biol. 1997; 23:767-776. [PubMed: 9253825]

Gargani L, Doveri M, D'Errico L, Frassi F, Bazzichi ML, Delle Sedie A, Scali MC, Monti S, Mondillo S, Bombardieri S, Caramella D, Picano E. Ultrasound lung comets in systemic sclerosis: a chest sonography hallmark of pulmonary interstitial fibrosis. Rheumatology (Oxford). 2009; 48:13821387. [PubMed: 19717549]

Lichtenstein D. Lung ultrasound in the critically ill. Curr Opin Crit Care. 2014; 20:315-322. [PubMed: 24758984]

Martelius L, Heldt H, Lauerma K. B-Lines on pediatric lung sonography: Comparison with computed tomography. J Ultrasound Med. 2016; 35:153-157. [PubMed: 26657749]

Mason KP, Lubisch NB, Robinson F, Roskos R. Intramuscular dexmedetomidine sedation for pediatric MRI and CT. AJR Am J Roentgenol. 2011; 197:720-725. [PubMed: 21862817]

Miller DL. Induction of pulmonary hemorrhage in rats during diagnostic ultrasound. Ultrasound Med Biol. 2012; 38:1476-1482. [PubMed: 22698500]

Miller DL, Dou C, Raghavendran K. Anesthetic techniques influence the induction of pulmonary capillary hemorrhage during diagnostic ultrasound scanning in rats. J Ultrasound Med. 2015a; 34:289-297. [PubMed: 25614402]

Miller DL, Dou C, Raghavendran K. Pulmonary capillary hemorrhage induced by fixed-beam pulsed ultrasound. Ultrasound Med Biol. 2015b; 41:2212-2219. [PubMed: 25933710]

Miller DL, Dou C, Raghavendran K. Dependence of thresholds for pulmonary capillary hemorrhage on diagnostic ultrasound frequency. Ultrasound Med Biol. 2015c; 41:1640-1650. [PubMed: 25746909]

Miller DL, Dou C, Dong Z, Raghavendran K. The influence of dexmedetomidine on ultrasoundinduced pulmonary capillary hemorrhage in rats. Ultrasound Med Biol. 2016; 42:964-970. [PubMed: 26774471]

Miller LA. Chest wall, lung, and pleural space trauma. Radiol. Clin. N. Am. 2006; 44:213-224. [PubMed: 16500204] 
O'Brien WD Jr, Simpson DG, Ho MH, Miller RJ, Frizzell LA, Zachary JF. Superthreshold behavior and threshold estimation of ultrasound-induced lung hemorrhage in pigs: role of age dependency. IEEE Trans Ultrason Ferroelectr Freq Control. 2003; 50:153-169. [PubMed: 12625588]

Raeman CH, Child SZ, Dalecki D, Cox C, Carstensen EL. Exposure-time dependence of the threshold for ultrasonically induced murine lung hemorrhage. Ultrasound Med Biol. 1996; 22:139-141. [PubMed: 8928311]

Volpicelli G. Lung sonography. J Ultrasound Med. 2013; 32:165-171. [PubMed: 23269722]

Weitzel WF, Hamilton J, Wang X, Bull JL, Vollmer A, Bowman A, Rubin J, Kruger GH, Gao J, Heung M, Rao P. Quantitative lung ultrasound comet measurement: method and initial clinical results. Blood Purif. 2015; 39:37-44. [PubMed: 25660686]

Zachary JF, Sempsrott JM, Frizzell LA, Simpson DG, O'Brien WD Jr. Superthreshold behavior and threshold estimation of ultrasound-induced lung hemorrhage in adult mice and rats. IEEE Trans Ultrason Ferroelectr Freq Control. 2001; 48:581-592. [PubMed: 11370372] 

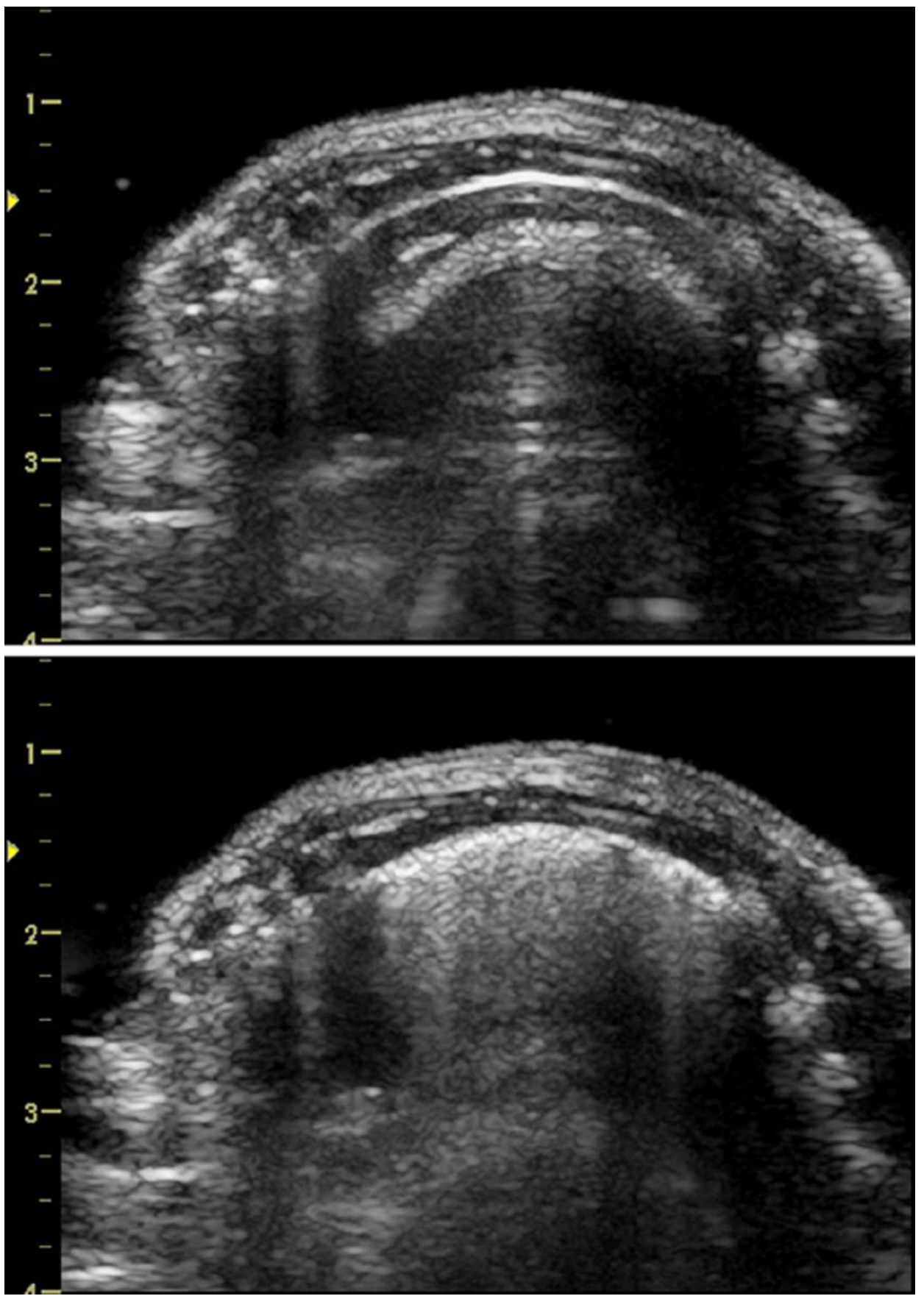

Figure 1.

Ultrasound images of the right side of a rat before (top) and after (bottom) scanning at $0 \mathrm{~dB}$ for 100s (group D). The sternum and spine are on the left and right of the images, respectively. The bright curved line about $5 \mathrm{~mm}$ deep into the thorax is the lung surface, and the deeper features in the images are multiple reflection artifacts. The bottom image shows the comet tail artifacts which grow downward from the bright surface image during scanning and represent multiple scattering from regions with pulmonary capillary hemorrhage. 

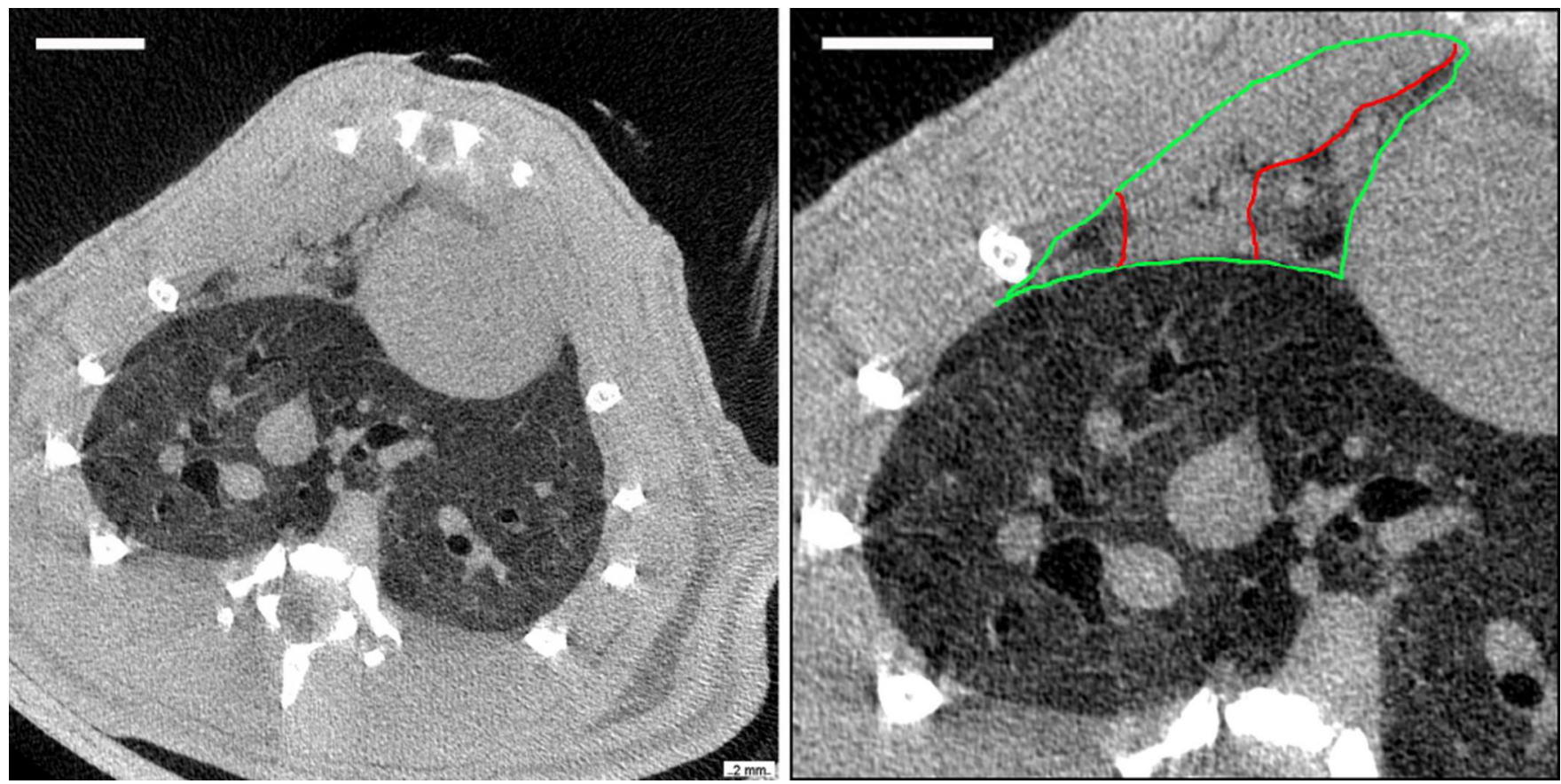

Figure 2.

Micro-computed tomography $(\mu \mathrm{CT})$ images of the same rat shown in Fig. 1, presented in radiology format (i. e. the right side of the rat is on the left). The left image is a cross section of the thorax showing bone in white, tissue as light grey and lung as dark grey (air is black, scale bar $5 \mathrm{~mm}$ ). The right image shows a close up of the right lung with the large caudal lobe appearing normal. The medial lobe (outlined in green) shows pulmonary capillary hemorrhage (outlined in red) throughout most of the lobe (scale bar $5 \mathrm{~mm}$ ). 

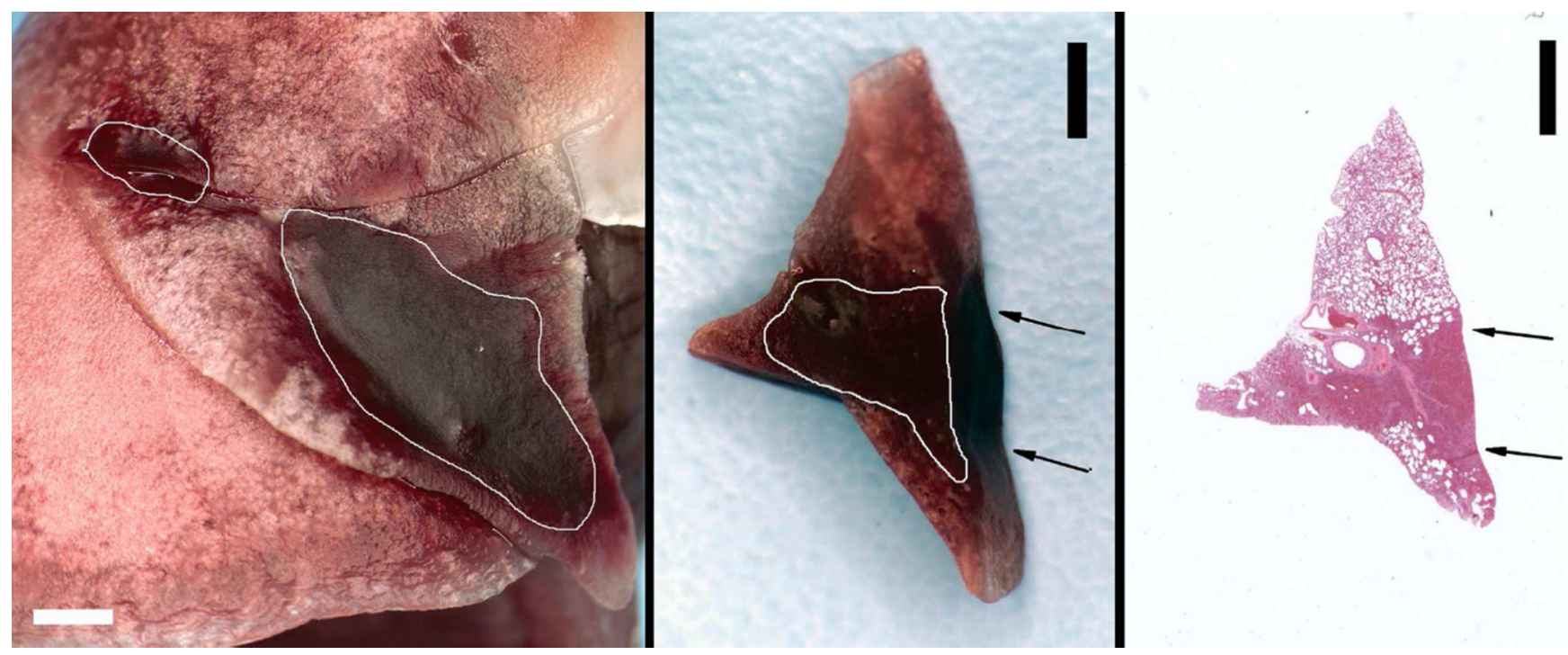

Figure 3.

The fixed lung sample for the tissues shown in Fig. 1 and Fig. 2. The left image of the lung surface shows the large pulmonary capillary hemorrhage $(\mathrm{PCH})$ in the medial lobe, and a smaller PCH area in the cranial lobe outlined in white (scale bar $2 \mathrm{~mm}$ ). A cross-section slab of the medial lobe $\mathrm{PCH}$ is shown in the middle picture with the area of apparent hemorrhage outlined in white (scale bar $2 \mathrm{~mm}$ ). The slab was about $2 \mathrm{~mm}$ thick and the front surface is visible in the image. The arrows show the incident direction of the ultrasound. The right picture shows a histological section with hematoxylin and eosin staining made from the cross section slab with the $\mathrm{PCH}$ area clearly visible (scale bar $2 \mathrm{~mm}$ ). 


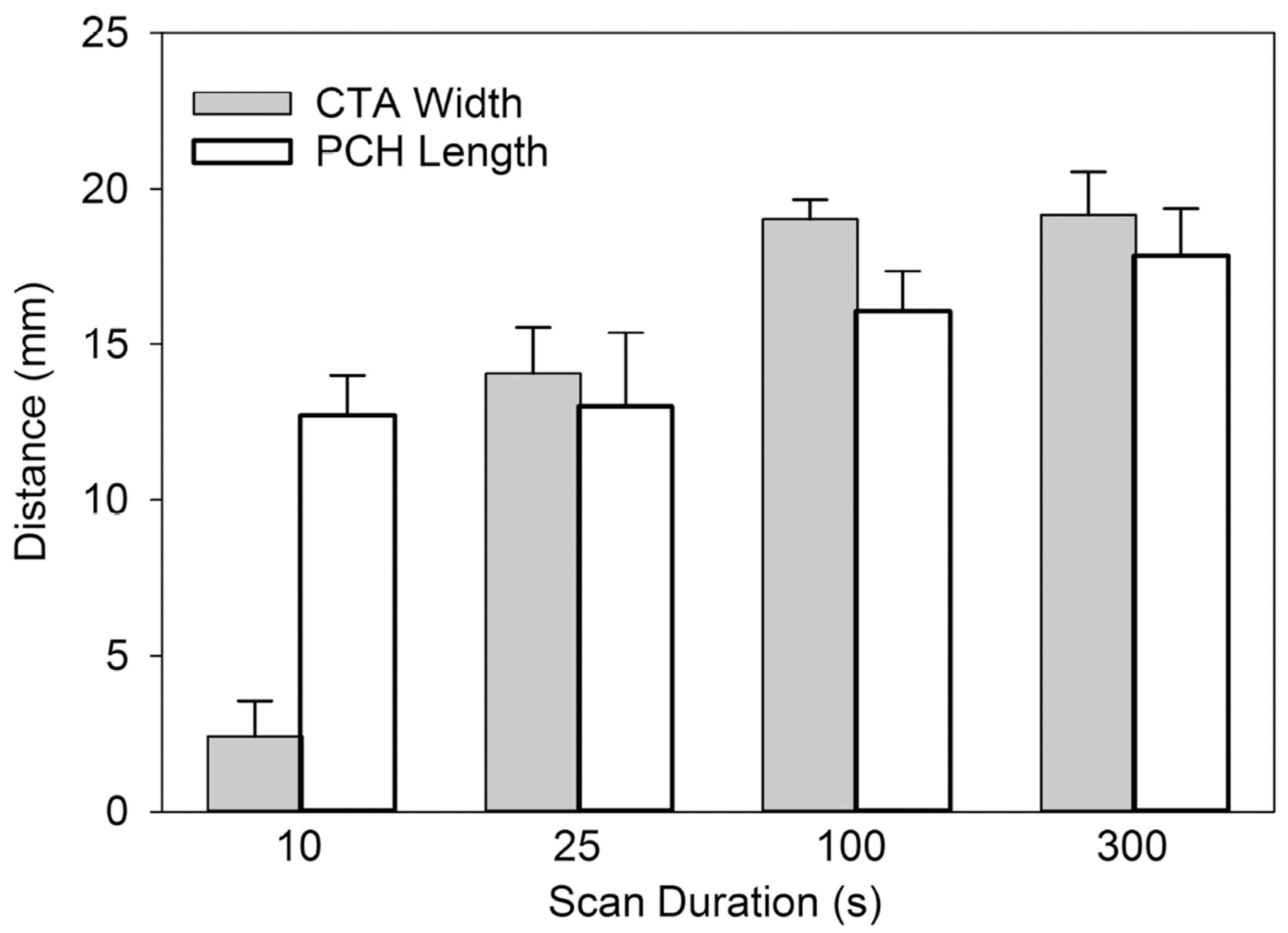

Figure 4.

The length of the comet tail artifacts across the bright line image (see Fig. 1) is compared to the length of the pulmonary capillary hemorrhage $(\mathrm{PCH})$ region measured along the scan plane seen in the fixed tissue (see Fig. 3). The ultrasound image was accurately diagnostic of the PCH seen on the surface except for the $10 \mathrm{~s}$ duration scans, for which the PCH was not always detected. 

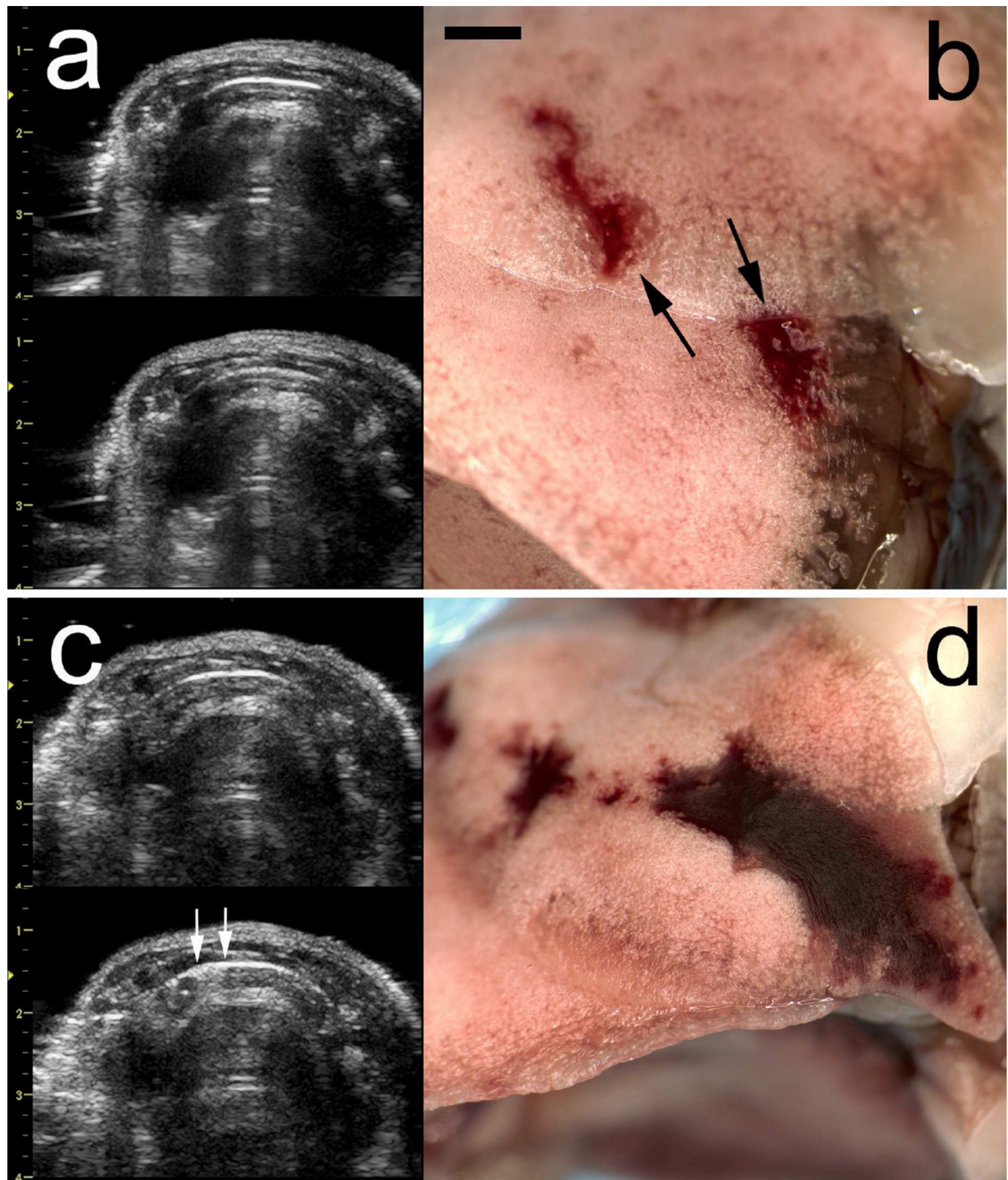

Figure 5.

A comparison of two results for $10 \mathrm{~s}$ scans (scale bar $2 \mathrm{~mm}$ ). The end-of-scan image (a, leftbottom) does not show any discernable comet tail artifacts relative to the start-of-scan image (a, left-top) associated with the pulmonary capillary hemorrhage (PCH) in (b). The PCH (a, right) was partly on the cranial and partly on the medial lobes, which shifted slightly during handling as indicated by the arrows. The PCH (b right) was sufficiently large to appear in the end-of-scan ultrasound image (b, right-bottom) as CTAs (indicated by the arrows). 


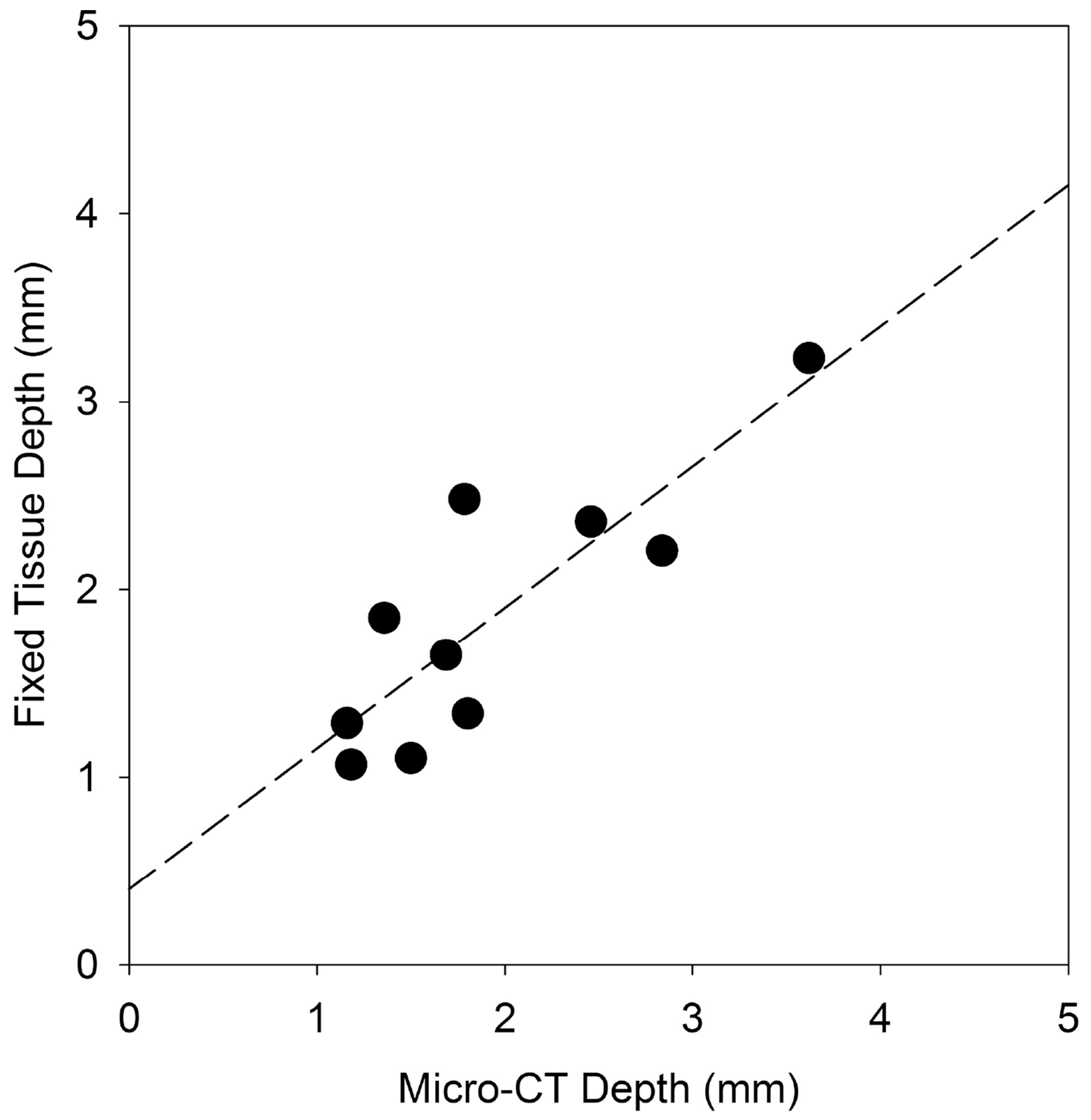

Figure 6.

A comparison of the pulmonary capillary hemorrhage depths determined from the fixed tissue samples and from the micro-computed tomography $(\mu \mathrm{CT})$ images. The two measurements were in reasonable agreement: the linear regression has a slope of 0.75 and coefficient of determination $r^{2}=0.72$. 


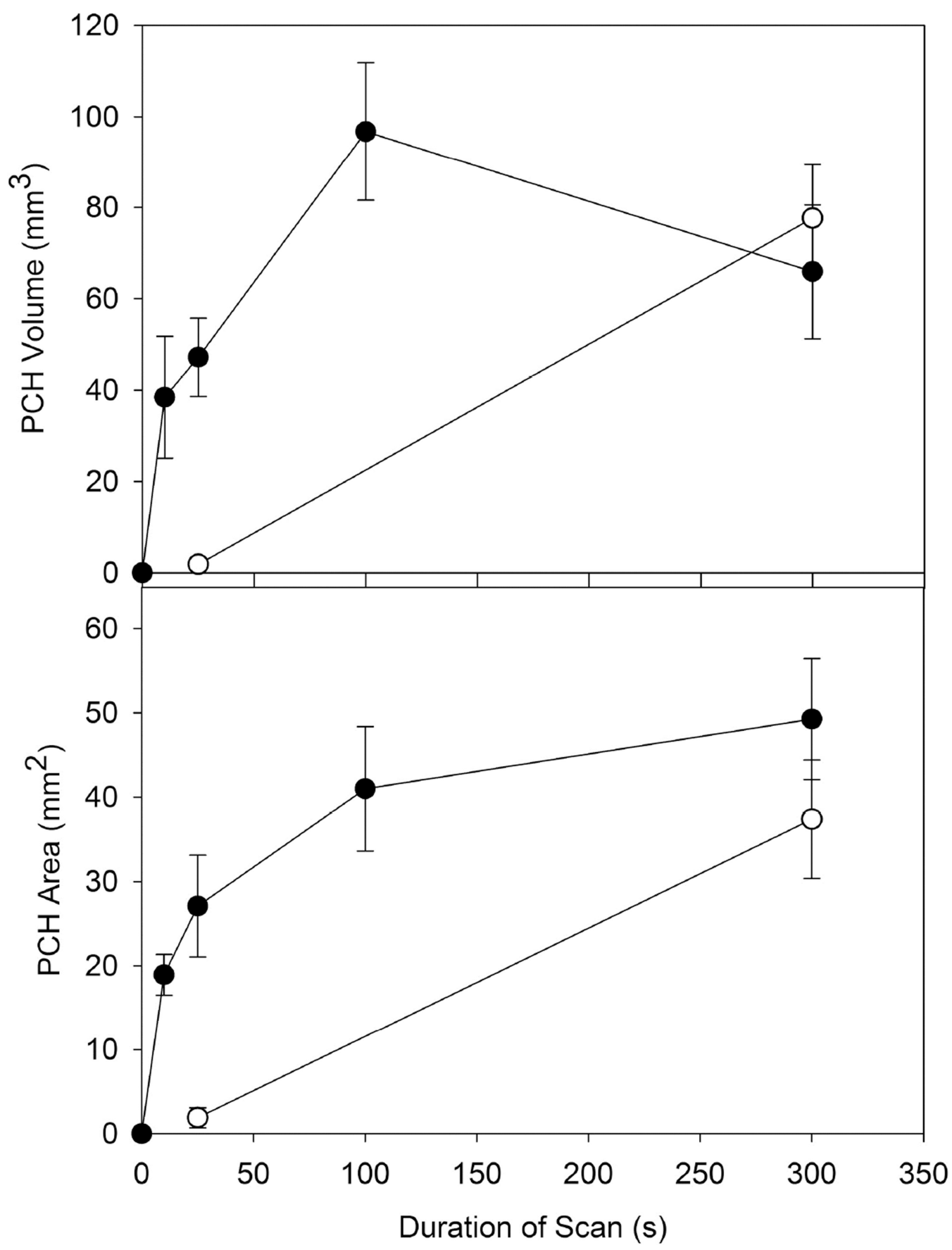

Figure 7.

The results for pulmonary capillary hemorrhage $(\mathrm{PCH})$ area and volume obtained from measurements of the fixed tissue samples. The results for $0 \mathrm{~dB}$ scans (filled circles) and -3 $\mathrm{dB}$ scans are compared for different scan durations. While the $\mathrm{PCH}$ was not significant for $25 \mathrm{~s}$ scans at $-3 \mathrm{~dB}$, even the $10 \mathrm{~s}$ scans produced significant $\mathrm{PCH}$ at $0 \mathrm{~dB}$. 


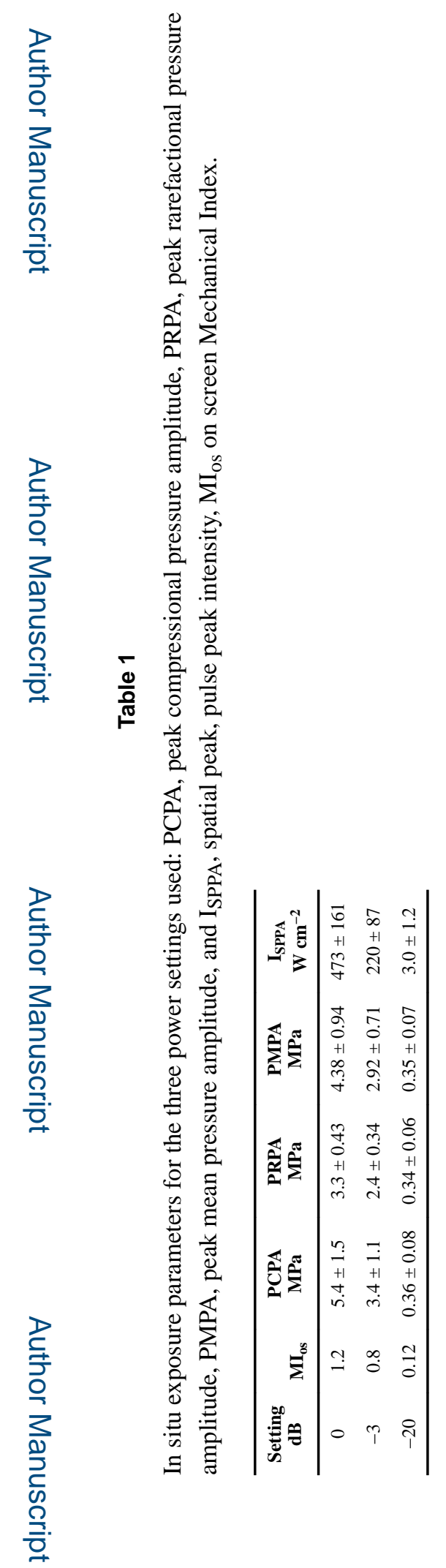




\section{Table 2}

Conditions set for the eight groups of 5 rats. The power setting was in $\mathrm{dB}$ on the machine (exposure parameters are listed in Table 1). The setting for frames per second (fps) was the normal B mode value, except the intermittent trigger feature was used to set the $5 \mathrm{fps}$ condition.

\begin{tabular}{ccccc}
\hline Group & $\begin{array}{c}\text { Power } \\
\text { decibels }\end{array}$ & Durations & $\begin{array}{c}\text { fps } \\
\mathbf{s}^{-1}\end{array}$ & $\begin{array}{c}\boldsymbol{\mu C T} \\
\mathbf{n}\end{array}$ \\
\hline A & sham & 300 & 63.1 & 2 \\
B & 0 & 300 & 63.1 & 5 \\
C & -3 & 300 & 63.1 & - \\
D & 0 & 100 & 63.1 & 5 \\
E & 0 & 25 & 63.1 & - \\
F & -3 & 25 & 63.1 & - \\
G & 0 & 10 & 63.1 & - \\
H & 0 & 300 & 5 & - \\
\hline
\end{tabular}




\section{Table 3}

Data for the length of the PCH on the lung surface from the width of comet tail artifacts (CTA) on the bright line (BL) image of the lung surface and from macroscopic measurement of the PCH seen on the fixed lung.

\begin{tabular}{ccccc}
\hline Group & $\begin{array}{c}\text { BL } \\
\mathbf{m m}\end{array}$ & $\begin{array}{c}\text { CTA width } \\
\mathbf{m m}\end{array}$ & $\begin{array}{c}\text { PCH Length } \\
\mathbf{m m}\end{array}$ & $\mathbf{p}$ \\
\hline A & $16.3 \pm 2.9$ & 0 & 0 & - \\
B & $20.5 \pm 2.3$ & $19.1 \pm 3.1^{*}$ & $18.4 \pm 3.7^{*}$ & nsd \\
C & $19.7 \pm 2.3$ & $15.2 \pm 2.3^{*}$ & $16.2 \pm 6.6^{*}$ & nsd \\
D & $20.4 \pm 1.7$ & $19.0 \pm 1.5^{*}$ & $16.1 \pm 2.8^{*}$ & nsd \\
E & $18.2 \pm 1.6$ & $14.1 \pm 3.4^{*}$ & $13.0 \pm 5.3^{*}$ & nsd \\
F & $15.8 \pm 1.7$ & $0.6 \pm 1.3$ & $1.7 \pm 2.0$ & nsd \\
G & $16.3 \pm 3.2$ & $2.4 \pm 2.5$ & $12.7 \pm 2.8^{*}$ & $<0.001$ \\
H & $18.8 \pm 3.6$ & $10.5 \pm 7.4^{*}$ & $10.6 \pm 6.3^{*}$ & nsd \\
\hline
\end{tabular}

Values which were significantly different from shams $(\mathrm{p}<0.05)$ are marked *. In addition, the statistical $\mathrm{p}$ value of comparisons of the CTA width and $\mathrm{PCH}$ length are listed, with no significant difference (nsd) for $\mathrm{p}>0.05$. 


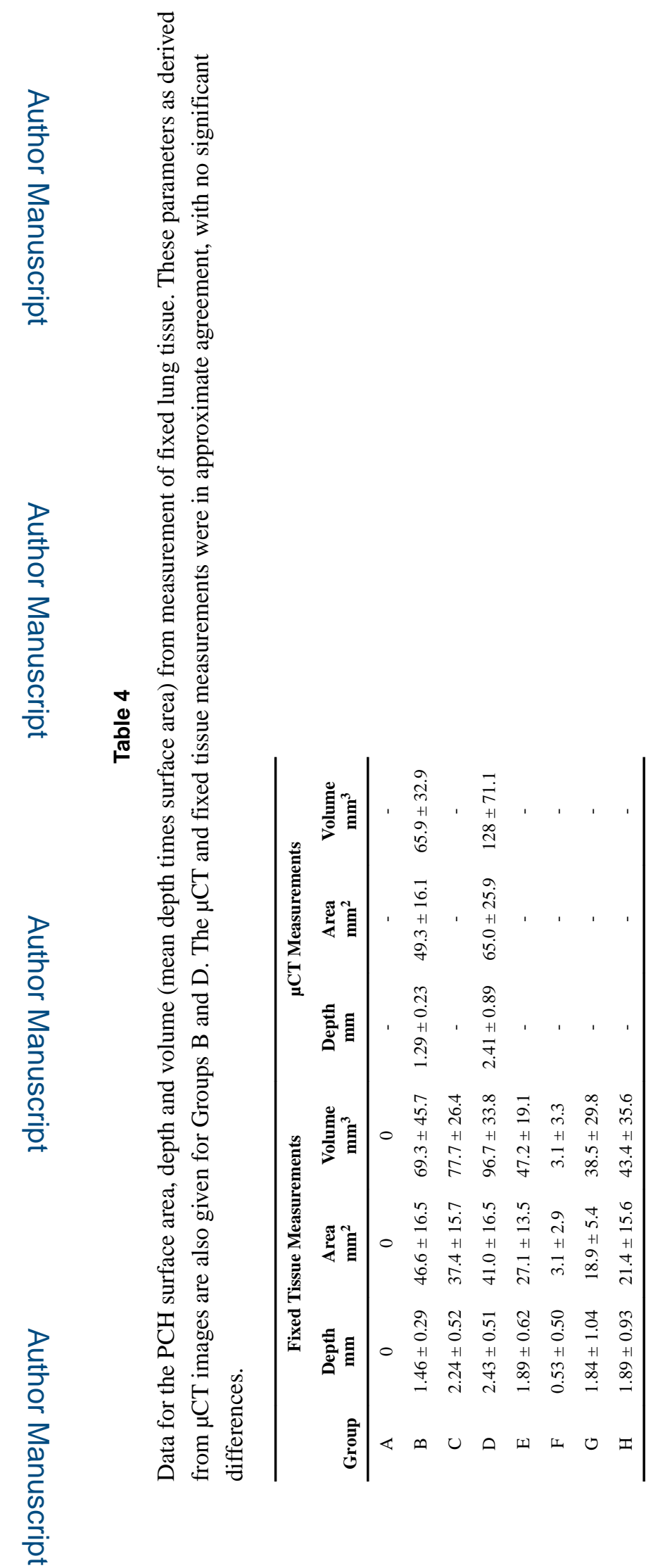

Ultrasound Med Biol. Author manuscript; available in PMC 2017 August 01. 